УДК 504.61:504.4:351.79

ЭКСТРЕМАЛЬНЫЕ НАВОДНЕНИЯ НА РЕКАХ ЮГРЫ

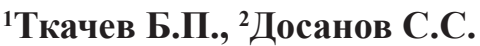

${ }^{l}$ ФББОУ ВО «Югорский государственный университет», Ханты-Мансийск, e-mail: btkachev@mail.ru; ${ }^{2} \mathrm{OOO} \mathrm{«Газпром} \mathrm{добыча} \mathrm{Ямбург»,} \mathrm{Новый} \mathrm{Уренгой,} \mathrm{е-mail:} \mathrm{sibdos73@gmail.com}$

Статья посвящена значимому природному феномену, имеющему прикладное значение - экстремальным наводнениям весенне-летнего половодья. Основные задачи: прогноз рисков, обусловленных прохождением волны половодья, предупреждение населения и снижение вероятного эколого-экономического ущерба территориям путем корректировки нормативных документов, принятия управленческих решений и проведения превентивных мероприятий. Для достижения этого, в первую очередь, следует оценивать величину самых крупных, экстремальных наводнений. Следует учитывать, что главной особенностью водных ресурсов Югры является их транзитность, когда основная часть вод поступает с Обью и Иртышом извне, а ресурсы речных вод заметно изменяются от года к году из-за чередования многоводных и маловодных лет. Выявлено, что экстремальные половодья являются цикличным природным процессом на реках региона с высокой повторяемостью (половодье 2015 г. повторяется обычно раз в 16 лет, 2007 г. - раз в 9 лет). Для этого были проанализированы результаты измерений с конца XIX в. Другой особенностью ресурсов поверхностных вод является их неустойчивость в течение года. Экстремальные весенне-летние половодья 2007 и 2015 гг. выявили необходимость проведения целого ряда правовых и организационных мероприятий по защите населенных пунктов Югры от наводнений и подтоплений. В работе также определена роль основных факторов весенне-летнего половодья в годы экстремальных наводнений и оценены уровни экстремальных половодий, прежде всего для транзитных рек Югры - Оби и Иртыша. В заключение представлен накопленный опыт прогнозирования рисков возникновения ЧС и расчета ущерба от наводнений.

Ключевые слова: наводнение, река, Обь, Иртыш, ущерб

\title{
EXTREME FLOODING ON THE RIVERS OF YUGRA
}

\author{
${ }^{1}$ Tkachev B.P., ${ }^{2}$ Dosanov S.S. \\ ${ }^{1}$ Yugra State University, Khanty-Mansiysk, e-mail: btkachev@mail.ru; \\ ${ }^{2}$ Gazprom dobycha Yamburg, Novy Urengoy, e-mail: sibdos73@gmail.com
}

\begin{abstract}
The Article is devoted to a significant natural phenomenon of applied significance-extreme floods of the springsummer flood. The main objectives of the forecast of risks caused by the passage of the flood wave are to prevent the population and reduce the likely environmental and economic damage to territories by adjusting regulatory documents, making management decisions and carrying out preventive measures. To achieve this, first of all, it is necessary to assess the magnitude of the largest, extreme floods. Note that the main feature of the water resources of Ugra is their transitory, when the bulk of the water comes from the Ob and Irtysh from the outside, and river water resources significantly vary from year to year due to the alternation of wet and dry years. It was revealed that extreme floods are a cyclical natural process on the rivers of the region with high repeatability (the 2015 flood is usually repeated once in 16 years, 2007 once in 9 years). To do this, we analyzed the results of measurements from the end of the XIX century. Another feature of surface water resources is their instability during the year. Extreme spring and summer floods in 2007 and 2015 revealed the need for a number of legal and organizational measures to protect the settlements of Ugra from floods and flooding. The paper also defines the role of the main factors of spring and summer floods in the years of extreme floods and estimates the levels of extreme floods, primarily for the transit rivers Ugra-Ob and Irtysh. In conclusion, the accumulated experience of forecasting the risks of emergencies and calculating flood damage is presented.
\end{abstract}

Keywords: flood, river, Ob, Irtysh, damage

В последние десятилетия в мире и в России все более активно обсуждается проблема наводнений и других экстремальных гидрологических событий. Это связано с растущим масштабом потерь и ущербов от наводнений, составляющих существенную долю неблагоприятных последствий природных катаклизмов [1].

Наводнение рассматривается как сложное событие, происходящее на некоторой территории при совместном наступлении ряда случайных событий, разрушения объектов техносферы и причинения ущерба $[2$, с. 21$]$.
Основными причинами значительных и длительных подъемов воды в период весенне-летнего половодья являются: талый сток, снежно-дождевые паводки и заторы льда. Большие и катастрофические наводнения на реках бассейна рек Оби и Иртыша в XX в. были отмечены в 1908, 1912, 1914, 1923, 1941, 1947, 1957, 1970, 1979 гг. Максимальный вековой расход воды р. Обь наблюдался 9 июля 1941 г. у поста Белогорье и составлял 51,8 тыс. $\mathrm{M}^{3} / \mathrm{c}$.

Характеристику основных наводнений в Тюменской области дал А.А. Таратунин. Так, в 1974 г. по Ханты-Мансийскому ав- 
тономному округу ущерб от наводнения достиг 7135 тыс. руб., что в пересчете по курсу доллара США 1974 г. составлял 9467,9 тыс. долл. [3].

К сожалению, из анализа наводнений периода 1986-2010 гг., проведенного В.А. Семеновым для большинства рек России, выпадают Иртыш, Средняя и Нижняя Обь [4].

Главной особенностью водных ресурсов Югры является то, что основная часть речных вод $\left(67 \%\right.$, или 247 км$\left.^{3}\right)$ поступает в округ извне. До середины 1970-х гг. суммарный объем годового стока Оби и Иртыша «на входе» в округ из Томской и юга Тюменской области был выше [5].

Вся территория округа находится в зоне достаточной и избыточной водообеспеченности. Во время весенне-летнего половодья водность рек сильно возрастает. В этот период проходит до $70 \%$ годового стока рек.

Цель работы: выявление роли экстремальных наводнений весенне-летнего половодья XXI в. для корректировки нормативных документов, регулирующих деятельность по защите населенных пунктов Югры. Для достижения поставленной цели решались следующие задачи:

1. Оценка экстремального весенне-летнего половодья 2007 и 2015 гг.

2. Представление опыта прогнозирования рисков возникновения чрезвычайных ситуаций (ЧС) и расчета эколого-экономического ущерба от наводнений.

Западно-Сибирская равнина имеет предельно равнинный рельеф. Центральная часть равнины характеризуется тектонически обусловленным центростремительным типом заложения речной сети. Великие реки Обь и Иртыш выполняют транзитную роль, пересекая равнину с юга на север. Административные границы Югры проведены по водоразделам.

В центральной части исторически сложилась лиманно-дельтовая система, котловина, образованная боковым блужданием русел рек и широким развитием озерных водоемов в условиях высокого положения базиса эрозии.

Следует учесть, что среди показателей качества жизни человека в третьем тысячелетии на первое место выдвигается его безопасность [6, с. 10].

\section{Экстремальные весенне-летние половодья 2007 и 2015 га.}

Основными факторами весенне-летнего половодья Югры являются: осенняя влагозарядка почвогрунтов, максимальные запасы воды в снеге (снегозапасы), интен- сивность снеготаяния и осадки в период формирования половодья.

Осенью 2006 и 2014 гг. наблюдался значительный переизбыток влаги в бассейне Иртыша и превышение нормы на большей части округа.

За последние 40-45 лет продолжительность снежного периода в округе сократилась, в то время как во второй половине зимы (февраль-март) количество осадков увеличилось, наиболее существенное и повсеместное увеличение наблюдается в марте (на 30-80\%).

«В мае - июне 2007 г. на реках округа сложилась очень сложная гидрометеорологическая обстановка. Из-за большого количества осадков в течение длительного времени на всей территории Западно-Сибирской равнины произошло наложение дождевых паводков на волну половодья, что привело к формированию экстремально высоких уровней воды практически на всех реках территории округа, на притоках рек Оби и Иртыша максимум был на 1,0-1,75 м выше нормы. Так, уже к концу мая уровни воды превысили среднемноголетние значения максимальных уровней на реках Обь (Нижневартовск, Нефтеюганск, Лемпино, Сытомино, Белогорье), Иртыш (Горноправдинск, Сибирский, ХантыМансийск), Конда, Северная Сосьва (Игрим, Березово). В 2007 г. в результате весенне-летнего половодья оказались в зоне подтопления 69 населенных пунктов, а также промышленные объекты и дороги на территории 8 муниципальных районов» [7, с. 303].

В 2015 г. все реки округа вскрылись до середины мая, ранее среднемноголетних значений на 3-11 дней. Теплая погода апреля и мая значительно усилила динамику развития половодья. На основных притоках Средней Оби до устья Иртыш высшие уровни воды сформировались значительно раньше среднемноголетних дат, но были в пределах прогноза, только на реках Большой Юган и Назым отмечались отметки опасных уровней.

Режим весенне-летнего половодья Оби и Иртыша характеризовался более поздним (на 5-15 дней), по сравнению со среднемноголетними датами, формированием высших уровней воды и очень продолжительным периодом затопления речных пойм.

При прохождении высоких вод половодья в 2015 г. наиболее тяжелые условия сложились в населенных пунктах, расположенных на Средней Оби (Нижневартовский район и г. Нижневартовск). В Югре на Нижней Оби (участок Оби от слияния с Иртышом до границы округа) влияние высокого половодья оказало меньшее воздействие. 
В годы экстремального половодья 2007 и 2015 гг. основная вода Оби и Иртыша формируется выше по течению, на юге Западной Сибири, роль транзитного стока усиливается. Максимальные уровни воды Иртыша 2015 г. превосходили среднемноголетние значения, но были ниже уровней 2007 г.

Участок Нижней Оби в 2015 г. был менее многоводный, чем в 2007 г. (наиболее выдающийся весенний паводок последних лет). Это обусловлено малой, нежели в 2007 г., водностью Иртыша (рис. 1).

«Обычно половодье на Иртыше начинается раньше и река 10-15 дней подпирает Обь. В конце половодья наблюдается обратный подпор Обью Иртыша (обычно до середины июля)» [8, с. 46]. В 2015 г. Иртыш в своем нижнем течении в период прохождения высоких вод находился в подпоре от Оби с 19 июня до 7 июля.

В 2015 г. водность реки Средней Оби на участке с. Соснино («на входе» в округ) до устья Иртыша была наибольшей после 1979 г., за исключением Нижневартовска, где уровень воды составил 1061 см, что на 10 см ниже исторического максимума 1979 г. Это объясняется:

1. Большими снегозапасами на водосборах основных притоков Средней Оби (Томи, Кети, Чулыма и др.), а также большой приточностью в Новосибирское водохранилище.
2. Высокими среднемесячными температурами воздуха и обилием осадков на водосборах рек Средней Оби в период формирования половодья, что спровоцировало практически одновременный сток поверхностных вод в русло принимающей их р. Обь.

Максимальный расход на Новосибирском водохранилище на 12 мая 2015 г. составил $6246 \mathrm{~m}^{3} / \mathrm{c}$ (соответственно максимальный приток в водохранилище 11 мая составлял $8143 \mathrm{M}^{3} / \mathrm{c}$ ), максимальный расход воды на $\mathrm{p}$. Томь на посту Томска составил $11100 \mathrm{~m}^{3} / \mathrm{c}$ [9].

Таким образом, основной объем воды в р. Обь поступил из р. Томь (рис. 2), причем волна высоких вод Оби является следствием волны паводка Томи с наложением волн паводка р. Чулым и других притоков правобережья Оби. С учетом разницы времени добегания эти волны и сформировали экстремально высокие уровни воды в районе г. Нижневартовск. Волна максимальных сбросов с Новосибирской ГЭС поступила уже после достижения максимальных уровней воды на соответствующих участках Оби, что привело к продолжительному стоянию и медленному падению уровней воды. Новосибирская ГЭС является регулятором стока, оказывая сдерживающий эффект на момент максимальных сбросов.

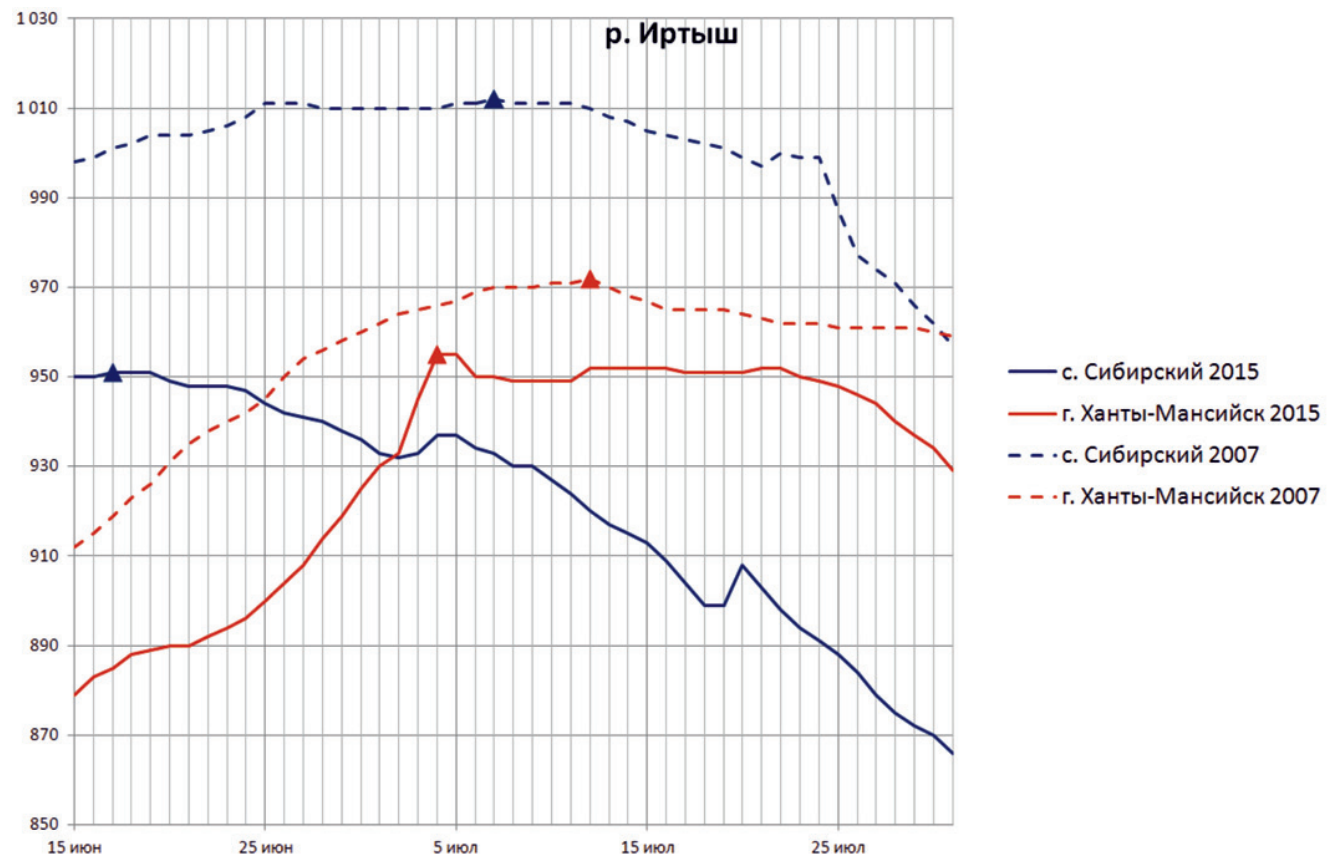

Рис. 1. Уровни воды р. Иртыли в период половодий 2007, 2015 г2. на постах Сибирский и Ханты-Мансийск 


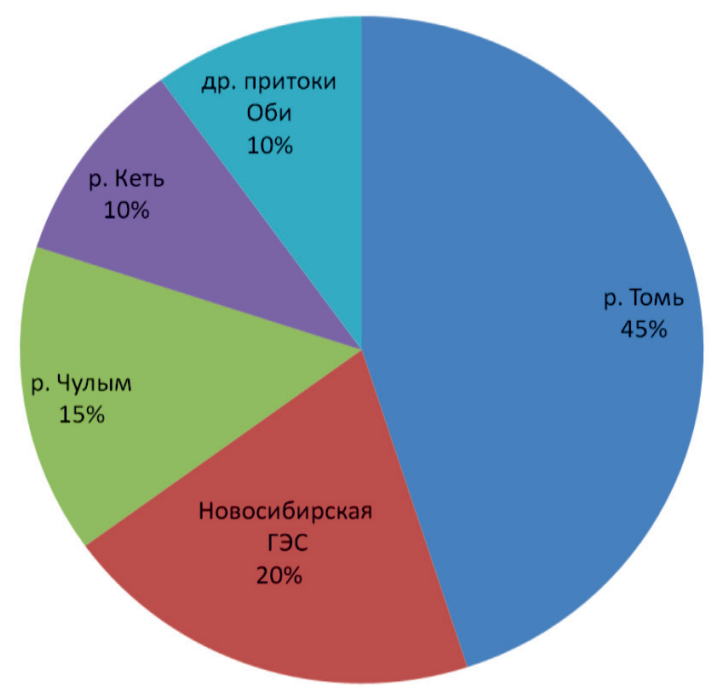

Рис. 2. Объем воды притоков р. Обь в период экстремальных уровней у поста Нижневартовск в 2015 г.

Прогнозирование и ущерб рисков возникновения ЧС от наводнений

Традиционно при прогнозировании используется метод соответствующих уров- ней воды, когда сравниваются данные постов наблюдений выше и ниже по течению реки. Для крупных транзитных рек Сибири - Оби и Иртыша, когда погрешности влияния притоков незначительны и ими можно пренебречь, такой метод имеет свои преимущества в оперативности (рис. 3).

Методика долгосрочного и краткосрочного прогноза уровней воды Оби и Иртыша разработана Д.А. Бураковым и др. [10-12].

Методы прогноза максимального расхода (уровня) воды, как правило, менее точны, чем методы прогноза стока за половодье. Это объясняется, главным образом, тем, что колебания интенсивности снеготаяния от года к году влияют на высоту половодья значительно сильнее, чем на объем весеннего стока [13].

Зависимость максимального расхода (уровня) воды от основных факторов (осенней влагозарядки почвогрунтов, максимальных снегозапасов, коэффициента дружности весны) не может быть положена в основу методов долгосрочных прогнозов высоты половодья по той причине, что точного детального долгосрочного прогноза интенсивности снеготаяния и осадков в период формирования половодья пока получить нельзя.

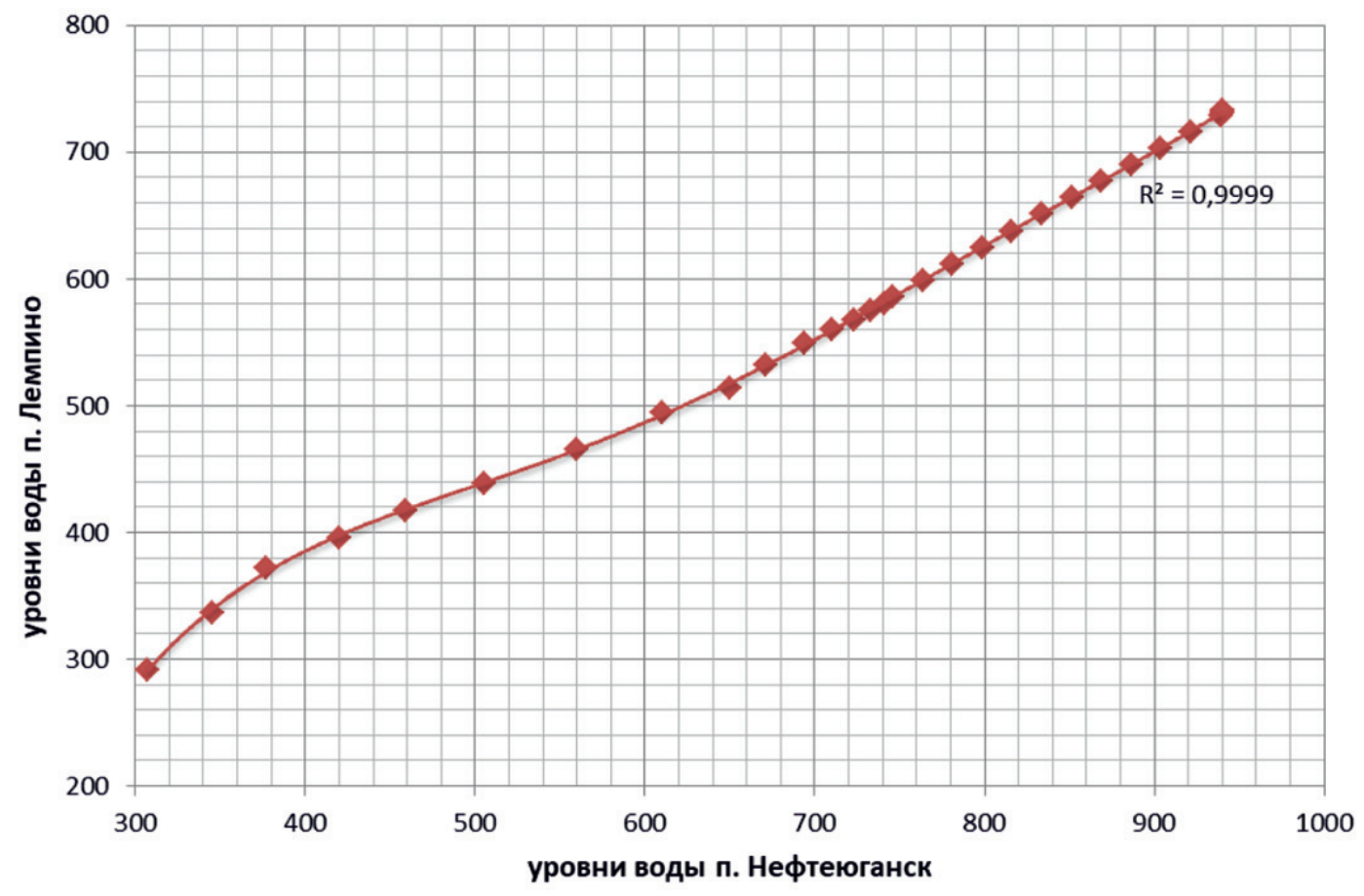

Рис. 3. График связи максимальных уровней воды р. Обь на постах Нефтеюганск и Лемпино в мае 2015 г. 
Предварительный прогноз рисков возникновения ЧС на период весенне-летнего половодья 2015 г. составлен 5 марта. На основе данных по снегозапасам и сложившихся за зиму гидрометеорологических условий оценены риски подтопления населенных пунктов, лежащих на притоках Оби и Иртыша. Оценить риски подтопления в населенных пунктах на реках Обь, Иртыш по снегозапасам территории округа невозможно, так как весенний сток этих рек формируется на водосборах за пределами автономного округа.

Основной прогноз по рискам прохождения паводковых вод по округу с детализацией по районам был составлен 4-16 апреля 2015 г. В прогнозе рассмотрены вероятности образования ледяных заторов в период вскрытия рек. Мониторинг и дальнейшие краткосрочные прогнозы развития и продвижения ледохода способствовали проведению ряда превентивных мероприятий по безаварийному пропуску льда (подрывы льда на Иртыше).

«Эколого-экономический ущерб - денежное выражение негативных последствий опасных событий, явлений и процессов. Для обеспечения комплексного управления водными ресурсами предполагается: усовершенствовать систему планирования развития водохозяйственного комплекса, повысить эффективность водного законодательства, согласованность действий и глубину анализа проблем» [2, с. 22].

При прогнозировании строятся карты затоплений, которые являются основой проведения градостроительной политики, a само картографическое моделирование бассейна позволит более точно оценивать площади, объекты экономики и сам ущерб, особенно экологический, в то время как экономический ущерб оценивается по отчетам муниципалитетов.

Проведенные исследования доказывают значимость гидрологических опасностей Средней и Нижней Оби. Опасность необходимо оценивать в первую очередь по частоте повторяемости наводнений, которые происходят в интервале 5-20 лет. Общая сумма эколого-экономического ущерба в связи с половодьем 2007 г. на территории Югры составила 121104 тыс. руб., в связи с половодьем 2015 г. - 67296 тыс. руб.

\section{Заключение}

Для заблаговременного прогнозирования и реагирования необходимо осуществление мониторинга р. Обь выше по тече- нию, за пределами округа - на территориях Томской и Новосибирской областей. Существует необходимость разработки методики расчета компенсации ущерба территориям, пострадавшим от наводнения и подтопления.

Экстремальные весенне-летние половодья 2007, 2015 гг. обусловили необходимость проведения корректировки «Реестра населенных пунктов на территории ХантыМансийского автономного округа - Югры, попадающих в зоны затопления (подтопления), вызванного различными гидрологическими и гидродинамическими явлениями и процессами». Предложено внести в Реестр населенные пункты с частотой подтопления не реже 1 раза в 10 лет.

В целях повышения качества мониторинга и обеспечения оперативных гидрологических прогнозов на территории округа необходимо обеспечить режим доступа для всех 48 гидропостов Югры, находящихся в системе Росгидромета. В настоящее время в оперативном режиме доступны данные только 33. Данные по еще 15 постам закрыты для потребителей и используются только для климатических обработок в системе Росгидромета.

\section{Список литературы / References}

1. Нафикова Э.В., Красногорская Н.Н., Белозерова Е.А., Соколова О.В. Анализ вероятности возникновения экстремальных гидрологических ситуаций на территории Республики Башкортостан // Велес. 2017. № 2-1 (44). C. $39-45$.

Nafikova E.V., Krasnogorskaya N.N., Belozerova E.A., Sokolova O.V. Analysis of the probability of occurrence of extreme hydrological situations on the territory of the Republic of Bashkortostan // Velez. 2017. № 2-1 (44). P. 39-45 (in Russian).

2. Ткачев Б.П. Гидрометеорологическое обеспечение устойчивого развития Севера (Арктики) // Безопасный Север - чистая Арктика: материалы I Всероссийской научнопрактической конференции (г. Сургут, 26 октября 2018 г.). Сургут: ООО Печатный мир, 2018. С. 14-25.

Tkachev B.P. Hydrometeorological support of sustainable development of the North (Arctic) // Bezopasny`j Sever chistaya Arktika: materialy' I Vserossijskoj nauchno-prakticheskoj konferencii (g. Surgut, 26 oktyabrya 2018 g.). Surgut: OOO Pechatny`j mir, 2018. P. 14-25 (in Russian).

3. Таратунин А.А. Наводнения на территории Российской Федерации. 2-е изд./ Под ред. Коронкевича. Екатеринбург: Изд-во ФГУП РосНИИВХ, 2008. 432 с.

Taratunin A.A. Floods on the territory of the Russian Federation. 2nd ed. / Pod red. Koronkevicha. Ekaterinburg: Izdvo FGUP RosNIIVX, 2008. 432 p. (in Russian).

4. Семенов В.А. Гидролого-климатические основы и география рисков опасных наводнений и маловодий на реках России // Научное обеспечение реализации «Водной стратегии Российской Федерации на период до 2020 года»: сборник статей. Петрозаводск: Карельский научный центр РАН, 2015. Вып. 2. С. 44-50.

Semenov V.A. Hydrological and climatic bases and geography of risks of dangerous floods and low water on the rivers of Russia // Nauchnoe obespechenie realizacii «Vodnoj strategii Rossijskoj Federacii na period do 2020 goda»: sbornik statej. 
Petrozavodsk: Karel’skij nauchny`j centr RAN, 2015. Vol. 2. P. 44-50 (in Russian).

5. Лёзин В.А. Реки Ханты-Мансийского автономного округа. Тюмень: Вектор бук, 1999. 156 с.

Lezin V.A. Rivers of the Khanty-Mansi Autonomous Okrug. Tyumen: Vector book, 1999. 156 p. (in Russian).

6. Малик Л.К. Факторы риска повреждения гидротехнических сооружений. Проблемы безопасности / Под ред. Н.И. Коронкевича. М.: Наука, 2005. 354 с.

Malik L.K. risk Factors for damage to hydraulic structures. Security problems Pod red. N.I. Koronkevicha. M.: Nauka, 2005. 354 p. (in Russian).

7. Досанов С.С., Ткачев Б.П. Влияние особенностей тектоники и морфологии русел рек на экстремальные наводнения в ХМАО-Югре // Нефть и газ Западной Сибири: материалы Междунар. научно-технической конф., посвященной 55-летию Тюменского государственного нефтегазового университета / Отв. ред. О.Ф. Данилов. Т. 4. Тюмень: ТюмГНГУ, 2011. С. 302-305.

Dosanov S.S., Tkachev B.P. Influence of features of tectonics and morphology of riverbeds on extreme flooding in the KHMAO-Yugra // Neft' i gaz Zapadnoj Sibiri: materialy` Mezhdunar. nauchno-texnicheskoj konf., posvyashhennoj 55-letiyu Tyumenskogo gosudarstvennogo neftegazovogo universiteta Otv. red. O.F. Danilov. T. 4. Tyumen`: TyumGNGU, 2011. P. 302-305 (in Russian).

8. Ткачев Б.П. Гидродинамические процессы устьевых областей реки Иртыш // Водное хозяйство России: проблемы, технологии, управление. 2015. № 4. С. 44-52.

Tkachev B.P. Hydrodynamic processes of the Irtysh river estuaries // Vodnoe xozyajstvo Rossii: problemy', texnologii, upravlenie. 2015. № 4. P. 44-52 (in Russian).

9. ПАО «РусГидро». [Электронный ресурс]. URL: http:// www.rushydro.ru/polovodie2018/ reki/ob/?date=2015-05-12 (дата обращения: 20.03.2020)

PJSC RusHydro. [Electronic resource]. URL: http://www. rushydro.ru/polovodie2018/ reki/ob/?date=2015-05-12 (date of access: 20.03.2020) (in Russian).

10. Бураков Д.А., Космакова В.Ф., Волковская Н.П Методика долгосрочного прогноза максимальных уровней воды для р. Обь у г. Нижневартовска и результаты их испытаний // Результаты испытаний новых и усовершенствованных технологий, моделей и методов гидрометеорологических прогнозов. 2017. № 44. С. 152-157.

Burakov D.A., Kosmakova V.F., Volkovskaya N.P. Method of long-term forecast of maximum water levels for the river. The Ob river near the city of Nizhnevartovsk and the results of their tests // Rezul'taty' ispy'tanij novy'x $\mathrm{i}$ usovershenstvovanny'x texnologij, modelej i metodov gidrometeorologicheskix prognozov. 2017. № 44. P. 152-157 (in Russian)

11. Бураков Д.А., Космакова В.Ф., Волковская Н.П. Методика долгосрочного прогноза максимальных уровней воды на реке Иртыш и результаты их испытаний // Результаты испытаний новых и усовершенствованных технологий, моделей и методов гидрометеорологических прогнозов. 2019. № 46. С. 71-78.

Burakov D.A., Kosmakova V.F., Volkovskaya N.P. Method of long-term forecast of maximum water levels on the Irtysh river and the results of their tests // Rezul'taty' ispy 'tanij novy'x $i$ usovershenstvovanny'x texnologij, modelej i metodov gidrometeorologicheskix prognozov. 2019. № 46. P. 71-78 (in Russian).

12. Бураков Д.А., Волковская Н.П., Иванова О.И. Автоматизированная методика краткосрочных прогнозов уровней воды в бассейне Средней Оби и Иртыша // Гидрометеорологические исследования и прогнозы. 2019. № 2 (372). C. $129-143$.

Burakov D.A., Volkovskaya N.P., Ivanova O.I. Automated method of short-term forecasts of water levels in the basin of the Middle $\mathrm{Ob}$ and Irtysh // Gidrometeorologicheskie issledovaniya i prognozy`. 2019. № 2 (372). P. 129-143 (in Russian).

13. Досанов С.С., Ткачев Б.П. Прогнозы опасных гидрологических явлений на территории ХМАО-Югры // Проблемы природной безопасности Югры: мониторинг и прогнозирование экстремальных гидрометеорологических явлений и лесных пожаров: сборник статей. Ханты-Мансийск, 2008. С. 59-61.

Dosanov S.S., Tkachev B.P. Forecasts of dangerous hydrological phenomena on the territory of KHMAO-Yugra // Problemy' prirodnoj bezopasnosti Yugry`: monitoring i prognozirovanie e'kstremal'ny'x gidrometeorologicheskix yavlenij i lesny`x pozharov: sbornik statej. Khanty-Mansiysk, 2008. P. 59-61 (in Russian). 